\title{
The role of teaching observations: Developing or managing academic practice?
}

Martin Compton

University of Greenwich

\begin{abstract}
"In four years teaching, you are the first person to observe me. I can't help thinking it might have been better for my students and me if it had happened sooner." Senior Lecturer at a London HEI

"This patchiness in the student experience within and between institutions cannot continue. There is extraordinary teaching that deserves greater recognition. And there is lamentable teaching that must be driven out of our system." Jo Johnson- Universities Minister - 9th September 2015
\end{abstract}

Teaching observations are well established in both the school and college sectors and, with the growth of Higher Education ( $\mathrm{HE}$ ) teaching programmes and the Higher Education Academy (HEA) fellowship scheme, they are becoming increasingly common in HE too. Given the talk of using outcomes from teaching observations as part of the Teaching Excellence Framework (TEF) metrics, it is important to understand both the real value of teaching observations and some of the potential pitfalls in their wider implementation.

A useful starting point when engaging in the teaching observations debate can be to reflect momentarily on what immediately springs to mind when this phrase is used. There is of course a plethora of models and a matching collection of often beguiling drivers underpinning observation programmes, with varying degrees of opacity. Who is doing the observing? What will they get from it? What will the observed person get? What power dynamics exist between the parties? How experienced or well trained are the observers? What exactly is being observed? Are there criteria against which the observed session is being judged? How does the feedback work? Is it reported or recorded? Our own perceptions and expectations as well as how we conduct ourselves when being observed or carrying out an observation will inevitably be shaped by personal experience.

I spent ten years professionally straddling further education (FE) and HE as a teacher trainer on PGCE and other teacher education programmes. In addition to observations of potential teachers at the recruitment stage and developmental observations on trainees, I also carried out 'quality', graded observations. I calculate that I have conducted more than 500 observations in those ten years. A recent shift to a teacher education role fully within HE, comments such as those in the epigraphs above and ongoing speculation about the likely impact of the TEF have given me cause to examine how my experiences might inform the debate around the role observations could or should play in HE. Observations of teaching in a range of guises have the potential to transform practice at individual and institutional level. There is always a danger, however, that they can become a resented consequence and instrument of marketisation and managerialism which feeds popular narratives of lazy teachers and lecturers only interested in long holidays or enhancing their research profiles. 


\section{Learning from "Cinderella's" experience}

Despite Ofsted's removal of individually graded lesson observations from September 2015 in FE (often referred to as the Cinderella sector), there has not been a deluge of institutions removing grading from their own observations. Despite a profusion of developmental observation projects across the sector, its bond to quality assurance will define a typical framework. Usually, all teaching staff are observed once a year, often by a manager and this is then graded against extensive standards drawing on the Common Inspection Framework (CIF) (Ofsted, 2014). Along with concerns about the validity and reliability of management driven and conducted observations, and about the measurability of such subjective concepts as 'outstanding' and 'good' teaching, there has been a growing discord between the research evidence against grading (see for example O'Leary, 2013) and many institutional policies of not only maintaining grading but also linking grades 3 and 4 (labelled: 'requires improvement' and 'unsatisfactory' respectively) to capability procedures, which can result in dismissal.

Many of the consequences of such systems were apparent in all the institutions I worked in and are reflected in Matt O'Leary's project report for UCU (2013b): normalisation of and focus on grading at the expense of developmental feedback; cynical compliance with a system leading to formulaic teaching sessions built around a perceived 'acceptable' structure; marked divisions between senior management and teaching staff perceptions of the worth and fairness of observations; an undermining and marginalisation of developmental and peer observation projects.

Take any FE policy on observation and I am confident it will be littered with words like 'developmental' and 'supportive'. Wrapping an accountability measure in improvement and support language in this way leads teaching staff to believe they are being misled by a management embarrassed by the system's true nature. Tweaks to observation policies, practices and outcomes become an annual battleground between trades unions and senior management teams. Some FE colleges have even gone so far as to claim they have removed grading, replacing it with a RAG rating system (Red, Amber, Green) or similar value-laden descriptors. It may not be numbers but it is grading all the same.

Jo Johnson's desire to recognise the extraordinary and drive out the lamentable suggests judgement mechanisms, not supportive or developmental ones. Within his statement sits a clear echo of discordant perspectives on the purpose of observations between FE leaders and the teaching staff. My fear is that statements such as his and a desire to implement teaching quality metrics might well create conditions wherein grading based on observations of some sort works its way into HE systems. If I put aside the largely developmental observations that are deemed necessarily pass/ fail on teacher training programmes, in any other context I would happily concur with this statement:

Grading lessons is a piece of lunacy so obviously open to misinterpretation, misunderstanding and abuse that it should be abandoned immediately (Didau, 2014, Online).

In addition to the grading debate there are also questions about the validity and reliability of observations as mechanisms for making such judgements in the first place. Professor 
Robert Coe (2013), for example, lists several examples of 'poor proxies' for learning which are often cited as essential elements of an outstanding teaching session such as:

Students are busy: lots of work is done (especially written work); Students are engaged, interested, motivated [and] Classroom is ordered, calm, under control. (p. xii)

Ho and Kane (2013) address issues of reliability in (school) observations and conclude that multiple observers are the best mechanism for improving reliability, noting that two sets of eyes more than doubles the reliability. Coe (op cit.) concludes that we have been measuring only those things that we can skew to show sought impacts have been achieved.

Governments may make policy decisions with apparent disregard for educational research evidence but it would constitute a particular kind of folly for HEls to do the same.

\section{Observations in HE}

HEls have followed divergent paths with regards to observations. Peer observation (often called 'peer review') systems are the most typical but even these can be viewed with suspicion if they are perceived as quality-driven judgement systems (see for example, Shortland, 2004). To say that use and enthusiasm is patchy is something of an understatement and this is likely to be due to suggested or imposed auditing demands, at least in part.

Considering all that I have said about the dangers, should I not be advocating the construction of barricades? In fact, I believe that there is an opportunity here to pre-empt likely, possibly even inevitable, drives to implement or develop observations systems and, above all, to be clear about what we want them to achieve. Particularly with an institutional commitment (and preferably backed up with appropriate resourcing), observations can be transformative and not only for those observed. Aside from the need to build genuinely collaborative relationships and other pre-requisites, peer observation projects in HE have proven successful in developing teaching attitudes and approaches. Bell and Mladenovic (2008), for example, highlight the value of the observation process to the peer observer, weighting its importance above that of the feedback given to the observed party. A study by Hendry et al. (2014) similarly concluded that through the process of being the observer, lecturing staff were able to positively change lecture and seminar practices. By definition, the structure of these peer observation projects subverts or reverses the oft-held assumption that the observer has some sort of authority or seniority.

In Shortland's (op cit.) case study the participants in a peer observation project "recognized that observation offers a tremendous potential to promote self-knowledge and personal development" (p. 227) despite their university's apparent managerialist agenda and failure to provide promised developmental resources. Hammersley-Fletcher and Orsmond (2004) report on two models of peer observation (a 'trios' model similar to that cited by Shortland above wherein each participant is observed by the other two in the group and a somewhat more formalized approach with experienced and trained peer observers conducting observations). In common with more recent research they conclude that establishing positive interpersonal relationships and providing constructive and developmental feedback are essential, but also suggest that there are benefits in the very process of observation training as well as in its subsequent application. 
Frequently cited barriers to success include a lack of clarity in objectives and processes as well as confidence in giving feedback to peers in terms of both the 'what' and 'how'. A 'hybrid' model described by Yiend et al. (2014) combines perspectives of both experienced observers and discipline specialist peers. They conclude from their data that:

the peer review model of teaching observation was only effective in prompting a reflective approach to observation when those participating had an adequate understanding of its meaning and implementation (op cit., pp.480-481).

There are other models that can be used to suit different contexts and needs, some of which are relatively untested in HEls. One is the Japanese lesson study method which appears to be growing quite significantly in the schools sector. In this process teachers collaborate on planning taught sessions then, as equal stakeholders in the design, deconstruct the efficacy of the implementation. This model extends the already more democratic 'trios' model of multiple observers and further shifts the emphasis away from the teacher to the delivery and its impact.

Success of any model may not be dependent on a commitment to resourcing these projects or subsequent staff development opportunities but this would of course help enable their development and demonstrate institutional commitment. From the point of view of quality assurance and with the TEF in mind, fair resourcing might also encourage lecturers to report (confidentially) on the broad outcomes as a quid pro quo.

What is fundamental is an awareness of what drives an observation system and how different modes of organisation can make for very different outcomes. If we make the connection in our own minds between teaching improvement and observations and resist the assumptions that observations are about making judgements, then we have a mindset conducive to creating and valuing observation systems that engage and work. Commitment at institutional level needs to come in the form of adequate resourcing and a willingness to separate the observation process from the system of appraisal. We need to be clear about why and how we go about observations coupled with a recognition of the value of observational expertise to model effective practice or to facilitate training within whatever specific framework or model is embraced. The TEF is still embryonic and there are few in the sector that have no concerns about its ramifications, but it may well prove to be a real opportunity for establishing genuinely effective and developmental observation systems. What is certain is that if we sit back and wait to see what happens we might be worrying more about our own grades than the ones we are giving our students.

\section{Reference List}

Bell, A., \& Mladenovic, R. (2008). The benefits of peer observation of teaching for tutor development. Higher Education, 55 (6), 735-752.

Coe, R. (2013). Improving Education. A triumph of hope over experience. Inaugural Lecture of Professor Robert Coe, Centre for Evaluation and Monitoring, University of Durham, 18 June 2013. 
Didau, D. (2014). How can we make classroom observation more effective? [Online]. Available at: http://www.learningspy.co.uk/learning/can-make-classroom-observationeffective/ [Last accessed: $27^{\text {th }}$ October 2015]

Hammersley-Fletcher, L., \& Orsmond, P. (2004). Evaluating our peers: is peer observation a meaningful process? Studies in Higher Education, 29(4), 489-503.

Hendry, G. D., Bell, A., \& Thomson, K. (2014). Learning by observing a peer's teaching situation. International Journal for Academic Development 19 (4), 318-329.

Ho, A.D. and Kane, T. J. (2013). 'The Reliability of Classroom Observations by School Personnel'. Research Paper. MET Project. Bill \& Melinda Gates Foundation. Available at: http://files.eric.ed.gov/fulltext/ED540957.pdf [Last accessed: 27th October 2015]

Ofsted (2014). Common Inspection Framework 2012: Updated for September 2014. Manchester, Ofsted.

O'Leary, M. (2013a). Surveillance, performativity and normalised practice: the use and impact of graded lesson observations in Further Education colleges. Journal of further and higher education, 37(5), 694-714.

O'Leary, M. (2013b). Developing a National Framework for the Effective Use of Lesson Observation in Further Education. UCU.

Shortland, S. (2004). Peer observation: a tool for staff development or compliance? Journal of further and higher education, 28(2), 219-228.

Yiend, J., Weller, S., \& Kinchin, I. (2014). Peer observation of teaching: The interaction between peer review and developmental models of practice. Journal of Further and Higher Education, 38(4), 465-484. 